\title{
Preschool children's meal patterns analysed using the Food-Based Classification of Eating Episodes model
}

\author{
Hanna Sepp', Maria Lennernäs ${ }^{2}$ and Lillemor Abrahamsson ${ }^{3}$ \\ 'Department of Behavioural Sciences, Kristianstad University, Kristianstad, Sweden; ${ }^{2}$ Department of Medical Sciences, \\ Nutrition, Uppsala University, Uppsala, and Swedish Dairy Association R\&D, Stockholm, Sweden; ${ }^{3}$ Department of \\ Domestic Sciences, Uppsala University, Uppsala, Sweden
}

\section{Abstract}

Background: Because of changing food habits that may influence nutritional status it is important, especially in children, reproducibly to describe and analyse the timing and frequency of eating and the composition of different types of eating episodes.

Objective: To describe eating patterns of 3-5-year-old Swedish preschool children by analysing 7 day food records using the Food-Based Classification of Eating Episodes (FBCE) model.

Design: Food intakes were categorized into four types of "meals" and four types of "snacks", according to their food profile. Complete 7 day weighed and estimated food records for 109 children were processed and analysed.

Results: On weekdays the children ate significantly more frequently than on weekend days, having 5.6 and 5.2 eating episodes per day, respectively. More eating episodes were classified as "meals" on weekdays than on weekend days: $72 \%$ and $60 \%$, respectively. On average for the whole week, $43 \%$ of the daily energy intake was derived from "complete meals" (CM) and 34\% from "incomplete meals" (IM). CM contributed significantly more energy and more nutrients, except for calcium, than did IM. In low-quality snacks (LS), sucrose contributed with about one-third of the energy content and the nutrient density was low.

Conclusions: The qualitative FBCE model verified nutritional characteristics of the children's diet previously found in the same cohort by the traditional dietary assessment methods. Processing of the dietary data by the model to show the prevalence and temporal distribution of eating episodes appears to be an applicable tool for nutritional screening of children's eating patterns.

Keywords: eating episodes; frequency; meals and snacks; preschool children; timing

Received: 25 Oct. 2005; Revised: 14 Aug. 2006; Accepted: 16 Aug. 2006

\section{Introduction}

$\mathrm{T}$ raditionally used methods, such as recalls, records and food frequency questionnaires (FFQs), are not specifically suitable to collect information on the daily eating patterns of individuals, which may be essential (1). In addition, meal pattern data from different dietary studies are difficult to compare because when subjects are asked to define meals, the classifications (e.g. breakfast, sandwich meal, light meal, snack) are often subjective and not reproducible. Such classifications are a mixture of values alluding to an understood point in time or a certain composition of meals, and they are also related to traditions.

In this study a specific method, the Food-Based Classification of Eating Episodes (FBCE) model
(1), previously used only among adult subjects such as shift-workers (2), patients $(3,4)$, obese versus normal-weight men (5), and older self-managing and disabled women (6), was applied to describe the daily eating patterns of preschool children. The method classifies each eating episode based on the food ingredients rather than on the time when a meal is taken or on traditional vocabulary. The concept of eating pattern comprises time, frequency, food combinations and nutritional quality of the daily eating episodes.

According to several reports, dramatic shifts in the eating behaviour and physical activity patterns of children have taken place, and are currently taking place, in different parts of the world (7). The traditional meal patterns (e.g. breakfast, lunch and 
dinner) have given way to a more individualistic meal pattern. Parallel to this, more children are becoming overweight and obese (8).

Several reports call for more knowledge about how meal frequency and timing of intake affect the metabolic response to food intake and appetite control $(9,10)$. Timing is of specific interest because of differences in the metabolic response to eating with respect to the circadian rhythm phase shown in adults (11). Metabolic effects of different eating patterns are summarized in the Nordic Nutrition Recommendations (NNRs) of 2004 (12). Equal levels of energy intake can, depending on how and when the intake occurs, differently affect the regulation of food intake, metabolism and energy balance $(10,12)$.

For preschool children in Sweden, recommendations with regard to meal patterns have been published (13) and the NNR 2004 (12) includes recommendations regarding the distribution of the daily energy intake over eating episodes. Consequently, the extent to which these recommendations are followed could be a measure of the quality of a child's diet.

A previous dietary study on preschool children (14) showed that the energy intake can be similar although the macronutrient composition may differ significantly owing to different food composition of different eating episodes and with different frequency of eating. The aim of this study was to apply the FBCE model on the same dietary data specifically to examine the children's eating pattern.

\section{Subjects and methods}

Data were collected in a study performed in 1998 as part of a larger investigation of the food habits of preschool children. Both qualitative and quantitative methods were used (15). Data collection included weighed and estimated dietary recordings. The weight of all foods and drinks ingested at pre-school was recorded on an individual basis during 5 days (Monday to Friday). At home during 7 days (Monday to Sunday) the portion sizes were estimated using standard household measurements or with the help of the Meal Model, a booklet with illustrations of typical Swedish dishes, food items and portion sizes (16). Time of every eating episode was recorded but no definition of type of meal was given.

To be included in the study preschools had to meet several criteria. First, they had to prepare the meals in their own kitchen. Secondly, three meals per day were to be served: breakfast, lunch and an afternoon meal. Thirdly, all the preschools also had to fulfil the criterion of having 3-5-year-old children attending full time (i.e. being normally present at the preschool for at least $35 \mathrm{~h}$ per week). All parents were expected to be able to read and write Swedish. No information about ethnic background was collected. Details concerning study rationale, methods, participants' characteristics, compliance and quality control have been described previously (15).

Twelve preschools in a suburb of Stockholm were selected at random. In the present part of the study 109 out of 131 children who completed a 7 day food record were included. The remaining 22 children were excluded for the following reasons: nine had food records for only 5 or 6 days and 13 had food records only for preschool.

The children's weight (undressed) was measured to the nearest $0.1 \mathrm{~kg}$ using an electronic scale (Tanita, model 1618). For height measurements to the nearest $5 \mathrm{~mm}$, a stadiometer was used. Background data on age, weight, height and predicted basal metabolic rate (BMR) and reported energy intake are presented in Table 1.

\section{Data processing and statistical methods}

The eating episodes were classified according to the FBCE model as described in detail elsewhere (1). In brief, the classification is based on combinations of food items (dishes and beverages) divided into any of the seven food groups in the Swedish food circle (17), plus products with alcohol or sugar added and beverages with no energy. Food is divided into seven new groups, according to its nutrient profile, as follows: a: meat, fish, eggs, milk, cheese; b: cereals, bread, rice, pasta, potatoes, legumes; c: fruits, vegetables, roots; d: nuts, olives, avocados; e: fats, spreads, cream, fatty sauces; f: products to which white sugar is often added (soft drinks, sweets, ice-

Table I. Characteristics of the 109 children included in the study

\begin{tabular}{lcll}
\hline & $\begin{array}{l}\text { Boys } \\
(n=58)\end{array}$ & $\begin{array}{l}\text { Girls } \\
(n=51)\end{array}$ & $\begin{array}{l}\text { Total } \\
(n=109)\end{array}$ \\
\hline Age (months) & $55.5 \pm 10.0$ & $57.8 \pm 9.4$ & $56.6 \pm 9.7$ \\
Weight (kg) & $18.9 \pm 3.6$ & $18.9 \pm 2.9$ & $18.9 \pm 3.3$ \\
Height (m) & $1.07 \pm 0.08$ & $1.08 \pm 0.07$ & $1.08 \pm 0.06$ \\
Predicted BMR (MJ) & $3.9 \pm 0.3$ & $3.6 \pm 0.3$ & $3.8 \pm 0.3$ \\
Reported El (MJ) & $6.7 \pm 1.0$ & $6.2 \pm 1.0$ & $6.5 \pm 1.0$ \\
El/BMR & $1.7 \pm 0.2$ & $1.7 \pm 0.2$ & $1.7 \pm 0.2$ \\
\hline
\end{tabular}

Data are presented as means \pm SD.

BMR: basal metabolic rate; El: energy intake. 


\begin{tabular}{|c|c|c|c|}
\hline $\begin{array}{l}\text { Type of eating } \\
\text { episode }\end{array}$ & $\begin{array}{l}\text { Food components, } \\
\text { NFA }\end{array}$ & $\begin{array}{l}\% \text { of daily energy and nutrient } \\
\text { intake, NNRs of } 2004\end{array}$ & $\begin{array}{l}\text { Comparable FBCE } \\
\text { type }\end{array}$ \\
\hline Breakfast & $\begin{array}{l}\text { Porridge with milk, gruel, or yoghurt with cereals +a small } \\
\text { sandwich + fruit or juice }\end{array}$ & $20 \%$ & CM \\
\hline Intermediate meal & Fruit & $>5 \%$ & HS \\
\hline Lunch & $\begin{array}{l}\text { Potatoes/rice/pasta }+ \text { meat/fish/eggs/beans }+ \text { vegetables }+ \\
\text { bread + margarine }+ \text { fruit (optional) }\end{array}$ & $25 \%$ & $\mathrm{CM} / \mathrm{VM}$ \\
\hline Intermediate meal & Milk/yoghurt + sandwich/cereals/porridge + fruit & $15-20 \%$ & CM \\
\hline Dinner & $\begin{array}{l}\text { Potatoes/rice/pasta }+ \text { meat/fish/eggs/beans }+ \text { vegetables }+ \\
\text { bread }+ \text { margarine }+ \text { fruit (optional) }\end{array}$ & $25 \%$ & $\mathrm{CM} / \mathrm{VM}$ \\
\hline Evening intermediate meal & Porridge or milk and sandwich + fruit (optional) & $5-10 \%$ & $\mathrm{IM}$ or $\mathrm{CM}$ \\
\hline
\end{tabular}

NFA: Swedish National Food Administration (13); NNRs: Nordic Nutrition Recommendations of 2004 (I2); FBCE: Food-Based Classification of Eating Episodes. CM: complete meal; HS: high-quality snack; VM: vegan meal; IM: incomplete meal.

cream) and alcohol; and g: water, coffee, unsweetened light beverages.

Each eating episode is classified by the FBCE model into one of four types of "meal" or four types of "snack", according to the following combinations of food groups: complete meal (CM): $a+b+c$; incomplete meal (IM): $\mathrm{a}+\mathrm{b}$; vegan (i.e. strictly vegetarian) meal $(\mathrm{VM}): \mathrm{b}+\mathrm{c}$ and $\mathrm{d}$; less balanced meal (LB): $a+c$; high-quality snack (HS): $a$ or b or c; mixed-quality snacks (MS): a or b or $\mathrm{c}+\mathrm{d}$, e or $\mathrm{f}$ in combination or singly; low-quality snacks (LS): e and/or f; no-energy snacks (NE): g.

The different types of meal contain or lack food items from food groups representing key nutrients. For example, an IM lacks fruit and vegetables and therefore lacks a vitamin $\mathrm{C}$ source, among others; an LB lacks a starchy component, and a VM lacks an animal component.

In addition, the eating episodes, both "meals" and "snacks", were coded according to time of intake during the $24 \mathrm{~h}$ day.

Food intake data were processed by the dietary calculation software MATs: the Flexible (18), which includes the Swedish National Food Administration (NFA) database and the FBCE processing software. Recipes from the included preschools and a few new products were added to the existing database.

Windows Minitab was used to analyse descriptive data and to examine significant differences with paired $t$-tests. Results are presented as means, standard deviations (SD) and $p$-values. Differences were considered statistically significant if $p<0.05$. Pairwise comparisons of CM and IM, and of HS and LS, were done. Owing to different numbers of observations, testing the differences between other types of eating episodes was not relevant.

The results of the analysis of the 109 children's diet were compared with the eating patterns suggested for preschool children by the Swedish NFA (13) and in the NNRs of 2004 (12), both recommending four CM (according to the FBCE characteristics) per day: breakfast, lunch, an afternoon meal and dinner. One or two snacks are also included. The suggested composition of these intakes and the recommended daily energy distribution from eating episodes are presented in Table 2. The comparable classifications according to the FBCE model are also shown in this table.

The project protocol was approved by the ethics committee of the Faculty of Medicine, Uppsala University, Uppsala, Sweden.

\section{Methodological considerations}

Validity and reliability aspects of this preschool study have been reported previously (15). In brief, the weighed records at school and the estimated food records at home were pooled, as it was assumed that, given relevant dietary information, parents would be able to record their children's intake adequately. Furthermore, there was no significant difference in the energy intakes between weekdays and weekends. The mean energy intake/ basal metabolic rate (EI/BMR) was 1.7, which indicates that the food record data are reliable. For some children, the registered energy intakes were low on some days compared with their estimated energy requirements. However, none of these data was left out as the first author (HS) came to know the children and their parents well and to 
realize that the low energy values were due to reasons other than underreporting.

\section{Results}

\section{Frequency of different types of eating episode}

The average number of eating episodes was $5.65 \pm$ 0.8 for weekdays and $5.23 \pm 1.3$ for weekend days (Table 3). The difference was significant. Of all eating episodes, an average of $72 \%$ were classified as "meals" during weekdays, which differed significantly from the figure during weekend days $(60 \%)$. With regard to the distribution of eating episodes during weekdays, $\mathrm{CM}$ was the most common eating episode $(40 \%)$, followed by IM (lacking food group c, i.e. vegetables, roots, fruits) $(28 \%)$ and LS (with added sugar) $(14 \%)$. On weekend days IM was the most common eating episode ( $35 \%$ ), followed by LS $(24 \%)$ and CM (22\%). There were significant differences between weekdays and weekend days in frequencies of all meal types (CM, IM, VM, LB) and LS. Taken together, during weekdays the children in general ate more frequently. More importantly, they ate more "meals" and fewer LS than they did on weekend days.

Compared with the recommendations, the children had CM less frequently, about 2.3 times per day on weekdays and 1.2 times per day on weekend days (recommendation 4-5 times a day), and other types of eating episode more frequently (Tables 2 and 3 ).

Table 3. Frequency, per day, of eating episodes, classified according to the FoodBased Classification of Eating Episodes model, during 5 weekdays and 2 weekend days in 109 children aged $3-5$ years

\begin{tabular}{lllr}
\hline & Weekdays & Weekend days & \multicolumn{1}{c}{$P$} \\
\hline Complete meals (CM) & $2.26 \pm 0.58$ & $1.17 \pm 0.75$ & $<0.001$ \\
Incomplete meals (IM) & $1.59 \pm 0.79$ & $1.84 \pm 0.86$ & 0.003 \\
Less balanced meals (LB) & $0.20 \pm 0.22$ & $0.09 \pm 0.22$ & $<0.001$ \\
Vegan meals (VM) & $0.00 \pm 0.00$ & $0.03 \pm 0.10$ & 0.025 \\
High-quality snacks (HS) & $0.42 \pm 0.34$ & $0.47 \pm 0.60$ & 0.341 \\
Mixed-quality snacks (MS) & $0.32 \pm 0.34$ & $0.32 \pm 0.41$ & 0.917 \\
Low-quality snacks (LS) & $0.81 \pm 0.56$ & $1.28 \pm 0.80$ & $<0.001$ \\
No-energy snacks (NE) & $0.05 \pm 0.13$ & $0.04 \pm 0.18$ & 0.411 \\
Aggregated eating episodes & & & \\
Meals (CM+IM+LB +VM) & $4.05 \pm 0.64$ & $3.12 \pm 0.66$ & $<0.001$ \\
Snacks (HS +MS + LS +NE) & $1.60 \pm 0.76$ & $2.11 \pm 1.06$ & $<0.001$ \\
Average sum of episodes & $5.65 \pm 0.8$ & $5.23 \pm 1.3$ & $<0.001$ \\
\hline
\end{tabular}

Values are given as means $\pm \mathrm{SD}$, and paired $t$-test $p$-values.

\section{Temporal distribution of meals and snacks}

The average temporal distribution of meals and snacks per hour during $24 \mathrm{~h}$ in the group of children is shown in Figs 1 and 2. The difference in temporal distribution of eating episodes on weekdays compared with weekend days was seen mainly between the meals in the morning and during the day. On weekdays the composition, timing and frequency of eating episodes are regulated by the arranged preschool meals, while during the weekend the intake is more flexible. At the preschools, CM were served in the morning, at noon and in the afternoon. During weekend days compared with weekdays a greater part of the snacks seemed to be served in the middle of the day, while during weekdays a greater part of the snacks was served in the evening. About $2 \%$ of the meals and $9 \%$ of the snacks on weekdays and about $4 \%$ of the meals and $11 \%$ of snacks on weekend days were recorded after 20:00 h.

\section{Energy and nutrients in the classified eating episodes}

The average energy and nutrient contribution per day from the seven types of eating episode taking place during the 7 registered days is given in Table 4, and energy percentage $(E \%)$ and nutrient densities are given in Table 5. The average results represent averages for each child who had had each type of the seven eating episodes that supply energy. In Table 4, therefore, the sum of the figures for the seven eating episodes does not equal the total for the day. As a comparison, the children's average total intake per day is also shown. A pairwise comparison of $\mathrm{CM}$ and IM showed that $\mathrm{CM}$ contributed significantly more $(p<0.05)$ energy, protein, fat, carbohydrates, dietary fibre, vitamin $\mathrm{C}$ and iron than did IM. A pairwise comparison of HS and LS showed that LS contributed significantly more $(p<0.05)$ energy and, in spite of their lower nutrient density, also more protein, fat, carbohydrates, sucrose, calcium and iron than did HS.

The average size of each CM (and IM) was $25 \%$ of the daily intake that is comparable to NNR 2004 (Table 2). The average size of the MS and LS was bigger $(16 \%)$ than suggested $(5 \%)$ by NNR 2004. Owing to the different frequencies of these meals and snacks their total contribution to the daily energy intake varied (CM 43\%, IM 34\%, MS 6\%, LS $12 \%$ ).

The nutritional quality of the meals is shown in Table 5. Compared with NNR 2004 (12), the energy percentage of macronutrients was slightly 


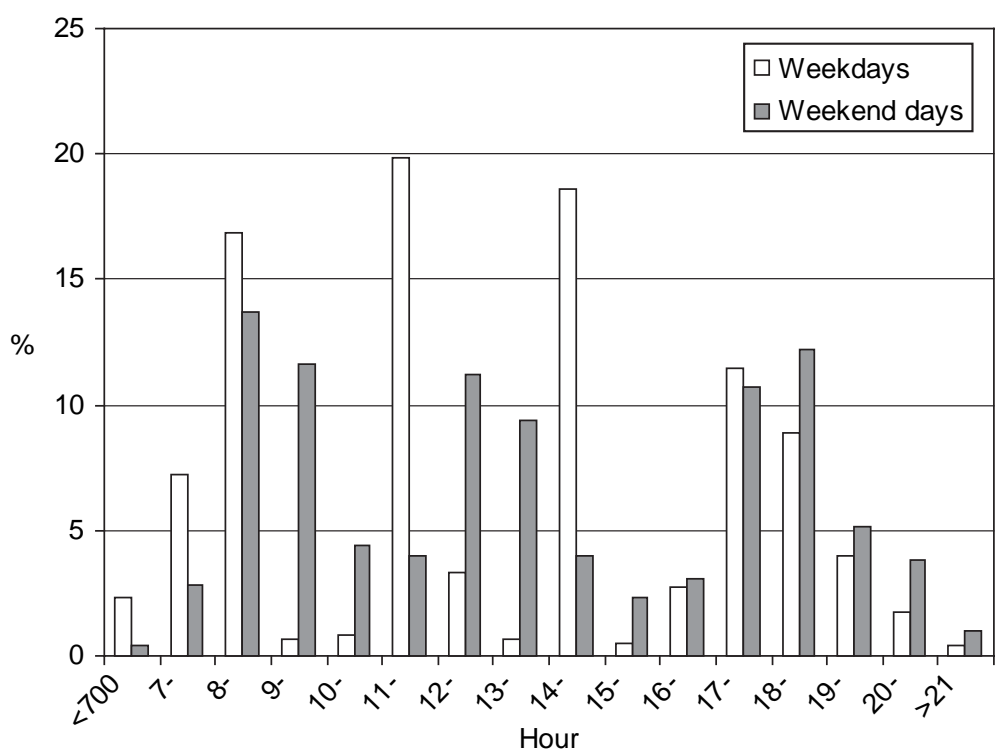

Fig. 1. Temporal distribution of meals [complete meals (CM)+incomplete meals (IM)+less balanced meals (LB)+vegan meals (VM)], classified according to the Food-Based Classification of Eating Episodes (FBCE) model, over 7 consecutive days in 109 preschool children aged $3-5$ years. Results are presented as mean percentage per day and hour on weekdays ( $n=448$ per day) and weekend days $(n=340$ per day).

unbalanced in all meals, with a high fat energy percentage and a low carbohydrate energy percentage, except in VM. In all snacks the energy percentage from carbohydrates was high. The sucrose content was high and made up about one-third of the energy in LS. A pairwise comparison showed that the density (amount per $\mathrm{MJ}$ ) of fibre and vitamin $\mathrm{C}$ was significantly $(p<0.05)$ higher and of calcium significantly $(p<0.05)$ lower in CM com- pared with IM. The difference between the nutrient density in HS and LS was significant $(p<0.05)$ for dietary fibre, vitamin $\mathrm{C}$, calcium and iron.

\section{Discussion}

The FBCE model, used to analyse data in this paper, yielded interesting results regarding the eating behaviour, i.e. occurrence and temporal distribution of eating episodes and their nutritional

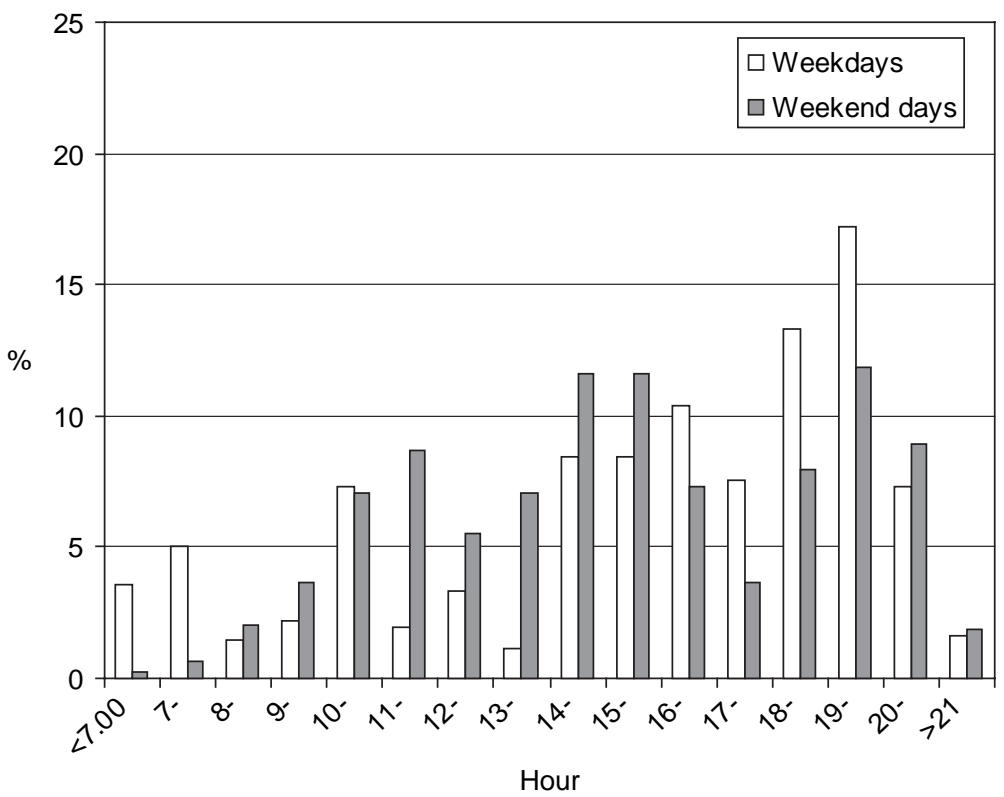

Fig. 2. Temporal distribution of snacking episodes [high-quality snacks (HS) + mixed-quality snacks (MS) +low-quality snacks (LS)], classified according to the Food-Based Classification of Eating Episodes (FBCE) model, during 7 consecutive days in 109 preschool children aged 3-5 years. Results are presented as mean percentage per day and hour on weekdays ( $n=164$ per day) and weekend days $(n=218$ per day). 
Table 4. Energy (MJ) and nutrient content ( $\mathrm{g}$ or $\mathrm{mg}$ ) in each type of eating episode per day classified according to the Food-Based Classification of Eating Episodes model

\begin{tabular}{|c|c|c|c|c|c|c|c|c|}
\hline \multirow[t]{2}{*}{ No. of children } & CM & IM & LB & VM & HS & MS & LS & Total \\
\hline & 109 & 109 & 73 & 38 & 97 & 86 & 109 & per day \\
\hline Energy (MJ) & $2.78 \pm 1.03^{\mathrm{a}}$ & $2.19 \pm 0.83^{a}$ & $0.25 \pm 0.16$ & $0.18 \pm 0.12$ & $0.16 \pm 0.12^{b}$ & $0.40 \pm 0.29$ & $0.78 \pm 0.46^{b}$ & $6.5 \pm 1.0$ \\
\hline Protein $(\mathrm{g})$ & $25.9 \pm 9.9^{\mathrm{a}}$ & $19.3 \pm 8.0^{\mathrm{a}}$ & $2.4 \pm 1.5$ & $0.7 \pm 0.5$ & $0.9 \pm 1.1^{\mathrm{b}}$ & $2.2 \pm 2.3$ & $2.3 \pm 1.4^{\mathrm{b}}$ & $52.5 \pm 10.5$ \\
\hline Fat $(\mathrm{g})$ & $26.6 \pm 9.8^{\mathrm{a}}$ & $21.2 \pm 8.9^{\mathrm{a}}$ & $2.6 \pm 1.8$ & $1.4 \pm 1.8$ & $0.6 \pm 1.0^{\mathrm{b}}$ & $3.1 \pm 2.8$ & $6.4 \pm 4.5^{\mathrm{b}}$ & $59.8 \pm 10.5$ \\
\hline Carbohydrates (g) & $79.9 \pm 32.0^{\mathrm{a}}$ & $63.1 \pm 25.1^{\mathrm{a}}$ & $6.5 \pm 5.5$ & $6.7 \pm 3.9$ & $7.1 \pm 5.2^{\mathrm{b}}$ & $14.3 \pm 10.6$ & $29.9 \pm 17.4^{b}$ & $197.8 \pm 37.5$ \\
\hline Sucrose $(g)$ & $11.7 \pm 7.0^{\mathrm{a} \mathrm{ns}}$ & $10.7 \pm 7.6^{\mathrm{ans}}$ & $1.8 \pm 2.1$ & $1.1 \pm 1.0$ & $2.0 \pm 1.6^{\mathrm{b}}$ & $5.3 \pm 5.1$ & $16.0 \pm 10.4^{b}$ & $46.8 \pm 16.1$ \\
\hline Dietary fibre $(\mathrm{g})$ & $5.1 \pm 2.1^{\mathrm{a}}$ & $3.3 \pm 1.5^{\mathrm{a}}$ & $0.4 \pm 0.4$ & $0.6 \pm 0.4$ & $0.9 \pm 0.7^{\mathrm{b} n s}$ & $0.9 \pm 1.0$ & $0.8 \pm 0.7^{\mathrm{b} \text { ns }}$ & $11.0 \pm 2.5$ \\
\hline Vitamin C (mg) & $35.0 \pm 19.0^{a}$ & $15.9 \pm 21.5^{a}$ & $4.2 \pm 4.6$ & $5.7 \pm 8.4$ & $6.6 \pm 6.0^{b} \mathrm{~ns}$ & $6.3 \pm 7.5$ & $5.1 \pm 7.3^{b \mathrm{~ns}}$ & $70.5 \pm 28.7$ \\
\hline Calcium (mg) & $332.5 \pm 143.6^{a}$ & $344.4 \pm 171.2^{a}$ & $38.0 \pm 32.1$ & $7.8 \pm 5.3$ & $19.5 \pm 30.3^{b}$ & $44.4 \pm 58.6$ & $45.1 \pm 31.9^{b}$ & $813 \pm 220$ \\
\hline Iron (mg) & $4.0 \pm 2.0^{\mathrm{a}}$ & $2.9 \pm 2.0^{\mathrm{a}}$ & $0.2 \pm 0.2$ & $0.2 \pm 0.1$ & $0.1 \pm 0.1^{b}$ & $0.4 \pm 0.5$ & $0.5 \pm 0.3^{b}$ & $8,0 \pm 2.5$ \\
\hline
\end{tabular}

The table gives averages for 7 days in those children out of a total of 109 children aged $3-5$ years who had consumed the classified meals or snacks. Data are presented as means \pm SD.

CM: complete meals; IM: incomplete meals; LB: less balanced meals; VM: vegan meals; HS: high-quality snacks; MS: mixed-quality snacks; LS: low-quality snacks.

a Pairwise comparisons, $p<0.05$.

${ }^{b}$ Pairwise comparisons, $p<0.05$.

ns: not significant $(p>0.05)$.

role, of preschool children. Results obtained were complementary to results usually obtained in dietary studies, such as data on energy and nutrient intake and the amount and frequency of food intakes, which have been presented elsewhere for this cohort (14).

The FBCE model showed that timing, frequency and the nutritional supply from the eating episodes were different on weekdays and weekend days. The children ate significantly more frequently during weekdays, confirming previous results from this study (14). Significantly more eating episodes dur- ing weekdays than on weekend days were classified as "meals". One out of four of the eating episodes on weekend days was classified as LS. In LS sucrose contributed to about one-third of the energy content. According to the NNRs of 2004, added refined sugars in total (sucrose, fructose, glucose and starch hydrolysates) should not exceed $10 E^{\%}$.

\section{Frequency and temporal distribution of eating episodes}

The FBCE model classified significant more eating episodes as meals and fewer as LB and LS during

Table 5. Energy percentage ( $E \%$ ) of macronutrients and nutrient density ( $\mathrm{mg} \mathrm{MJ}{ }^{-1}$ and $\mathrm{g} \mathrm{MJ}^{-1}$ ) per eating episode, classified according to the Food-Based Classification of Eating Episodes model

\begin{tabular}{|c|c|c|c|c|c|c|c|c|}
\hline & CM & IM & LB & VM & $\mathrm{HS}$ & MS & LS & NNRs \\
\hline No. of children & 109 & 109 & 73 & 38 & 97 & 86 & 109 & \\
\hline Protein $(E \%)$ & $16 \pm 2^{a}$ & $15 \pm 2^{a}$ & $18 \pm 9$ & $7 \pm 3$ & $9 \pm 7^{b}$ & $9 \pm 5$ & $5 \pm 1^{b}$ & $10-20$ \\
\hline Fat $(E \%)$ & $36 \pm 4^{\mathrm{a} n \mathrm{~ns}}$ & $36 \pm 6^{\mathrm{ans}}$ & $40 \pm 13$ & $25 \pm 16$ & $12 \pm 15^{b}$ & $27 \pm 13$ & $29 \pm 10^{b}$ & $25-35$ \\
\hline Carbohydrates ( $E \%)$ & $48 \pm 5^{\mathrm{a} n s}$ & $49 \pm 7^{\mathrm{a} n s}$ & $42 \pm 15$ & $68 \pm 15$ & $79 \pm 19^{b}$ & $64 \pm 16$ & $66 \pm 10^{b}$ & $50-60$ \\
\hline Sucrose $(E \%)$ & $7 \pm 3^{a}$ & $8 \pm 5^{a}$ & $11 \pm 9$ & $9 \pm 8$ & $21 \pm 11^{b}$ & $24 \pm 14$ & $35 \pm 10^{b}$ & $<10^{c}$ \\
\hline Dietary fibre $\left(\mathrm{g} \mathrm{MJ}^{-\mathrm{I}}\right)$ & $1.8 \pm 0.3^{\mathrm{a}}$ & $1.5 \pm 0.5^{\mathrm{a}}$ & $1.7 \pm 1.3$ & $3.8 \pm 3.0$ & $6.4 \pm 4.0^{b}$ & $2.1 \pm 1.5$ & $1.0 \pm 0.8^{b}$ & d \\
\hline Vitamin $C\left(m g ~ M J^{-1}\right)$ & $12.3 \pm 4.6^{\mathrm{a}}$ & $6.9 \pm 8.0^{\mathrm{a}}$ & $18.7 \pm 27.0$ & $39.9 \pm 71.4$ & $55.0 \pm 54.4^{\mathrm{b}}$ & $17.8 \pm 19.3$ & $7.2 \pm 7.1^{b}$ & d \\
\hline Calcium (mg $\mathrm{MJ}^{-1}$ ) & $120 \pm 28^{a}$ & $155 \pm 49^{a}$ & $152 \pm 100$ & $50 \pm 28$ & $111 \pm 136^{b}$ & $109 \pm 83$ & $57 \pm 25^{b}$ & d \\
\hline Iron $\left(\mathrm{mg} \mathrm{MJ} \mathrm{J}^{-1}\right)$ & $1.4 \pm 0.5^{\mathrm{a} n s}$ & $1.3 \pm 0.7^{\mathrm{a} n s}$ & $1.1 \pm 0.8$ & $1.2 \pm 0.4$ & $0.9 \pm 0.7^{b}$ & $0.9 \pm 0.7$ & $0.6 \pm 0.2^{b}$ & d \\
\hline
\end{tabular}

The table gives averages for 7 days in those children out of a total of 109 children aged 3-5 years who had consumed the classified meals or snacks, compared with Nordic Nutrition Recommendations (NNRs) of 2004. Data are presented as means \pm SD.

CM: complete meals; IM: incomplete meals; LB: less balanced meals; VM: vegan meals; HS: high-quality snacks; MS: mixed-quality snacks; LS: low-quality snacks.

${ }^{a}$ Pairwise comparisons $(p<0.05)$.

${ }^{\mathrm{a}} \mathrm{ns}=$ non-significant pairwise comparisons $(p>0.05)$.

${ }^{\mathrm{b}}$ Pairwise comparisons $(p<0.05)$.

${ }^{c}$ NNR 2004 recommends limitation to IOE\% of added purified sucrose, fructose, glucose and starch hydrolysates (I2).

d There are no NNRs of nutrient density for children below 6 years of age. 
weekdays than on weekend days. The most likely reason is that the food service at preschools ensured that the children's eating during weekdays at preschool followed the NFA guidelines (Table 2). The reason why $\mathrm{CM}$ were the most frequent eating episode during weekdays compared with IM during weekends is probably that fruits and/or vegetables were served with each meal at preschool (19). Another reason could have been that food habits on Saturdays and Sundays are more flexible owing to more flexible activities on such days, and that parents therefore may be less strict about their children's vegetable and fruit consumption. Data of this type on children's eating patterns could be useful in screening children's food habits related to health and other factors or evaluating the quality of the food service in schools.

\section{Frequency of snacks, and nutrient density}

Each snack episode on average contributed more than the $5 \%$ of the daily energy suggested for a snack by the NFA (13). The frequently consumed LS contributed an average of $12 \%$ of the children's energy intake for the 7 days. LS were considerably more frequent during the weekend. The previous analysis of food intake in this study, as mentioned in the Introduction, showed that low-nutrient-dense foods, e.g. confectionery, buns and soft drinks, contributed less to the energy intake during weekdays than during weekend days (19). Use of the FBCE model revealed the same diet characteristics. During weekends one-quarter of all eating episodes were classified as LS, which contained on average $35 E \%$ sucrose. The effect of the 109 children's different eating habits on weekdays and on weekend days was that the mean energy from sucrose at preschool was $9 E \%$, while at home during weekdays it was $12 E \%$ and on weekend days it was $16 E \%$ (14). Thus, the FBCE model seems applicable to identify sucrose-rich snacks even when data on consumed amounts are not collected. This is in accordance with results from studies of shift-workers (2), obese subjects and their lean controls (5), and elderly people (6).

There seems to be a trend in many societies towards high-energy and low-nutrient-dense foods rich in sugar and/or fat having a greater role in terms of energy. The consequences of this may be a reduction in dietary nutrient density (20) as well as an increased risk of overweight and obesity (21).
Although LS contributed considerable amounts of both energy and several nutrients to the children's intake in this study, as also reported in a study by Gatenby (9), the nutrient density was low in this type of snack owing to the high sucrose content. The previous report from the same preschool sample showed that on weekdays the children's diet had a significantly higher nutrient density for several nutrients and dietary fibre compared with weekend days. This result was probably caused by their eating pattern, with more CM and fewer LS on weekdays. There are diverging views about the effects of eating snacks on the energy balance, probably because snacks have not been uniformly defined in dietary studies (22-25). Tools such as the FBCE model, which categorize intakes, especially snacks, according to their combinations of different food items, appear to be worth testing in population studies with the aim of relating different food habits to body weight and obesity, for example.

\section{Optimal timing and frequency of eating}

Little is known about the nutritional or behavioural consequences of irregular eating and differences in the temporal distribution of intake among children (22). One reason may be that existing data on eating episodes and meal patterns have been difficult to compare between dietary studies (9). Since 1981, the Swedish Nutrition Recommendations (SNRs) have included composition, frequency, timing and distribution of daily food intakes in the general population (26). The new edition of the Nordic Nutrition Recommendations, NNR 2004, includes a section on scientific evidence concerning frequency and timing of eating (12). There are therefore new reasons to apply the official recommendations for the composition (13) and distribution over time (12) of children's meals. The FBCE model seems to be well suited for evaluating eating patterns against the official recommendations in a reliable way, independently of different cultures and eating habits of individuals. In the present study the evaluation of the studied children's eating patterns shows that there is room for improvement. A greater number of eating episodes needs to be supplemented with vegetables and fruit to be classified as $\mathrm{CM}$, and the frequency of LS should be reduced because of the low nutrient density and high sugar content in this type of eating episode. 


\section{Conclusions}

The FBCE model verified the nutritional characteristics of preschool children previously shown by traditional nutritional calculations in the same cohort. The eating episodes (type of meal or snack) differed with respect to food composition (e.g. prevalence of vegetables), nutrient composition and profile (i.e. $E \%$ sucrose and fat and nutrient density per MJ differed between snack types) and size (less energy in snacks than in meals), in line with the definition criteria. Processing of the dietary data by the model to show the prevalence and temporal distribution of eating episodes therefore appears to be an applicable tool for screening children's eating patterns, and for comparing them with the official recommendations.

\section{Acknowledgements}

The authors would like to thank the Swedish Dairy Association and the Faculty of Social Sciences, Uppsala University, for funding the study.

\section{References}

1. Lennernäs M, Andersson I. Food-Based Classification of Eating Episodes (FBCE). Appetite 1999; 32: 53-65.

2. Lennernäs M, Hambraeus L, Åkerstedt T. Nutrition and shiftwork: the use of meal classification as a new tool for qualitative/quantitative evaluation of dietary intake in shiftworkers. Ergonomics 1993; 36: 247-54.

3. Sidenvall B, Lennernäs M, Ek A. Elderly patients' meal patterns: a retrospective study. J Hum Nutr Diet 1996; 9: 263-72.

4. Wissing U, Lennernäs M, Ek A, Unosson M. Meal patterns and meal quality in patients with leg ulcers. $\mathbf{J}$ Hum Nutr Diet 2000; 13: 3-12.

5. Andersson I, Lennernäs M, Rössner S. Meal pattern and risk factor evaluation in one-year completers of weight reduction program for obese men - the "Gustaf" study. J Intern Med 2000; 247: 30-8.

6. Andersson J, Gustafsson K, Fjellström C, Sidenvall B, Nydahl M. Meals and energy intake among elderly woman - an analysis of qualitative and quantitative dietary assessment methods. J Hum Nutr Diet 2001; 14: 467-76.

7. St-Onge M-P, Keller KL, Heymsfield SB. Changes in childhood food consumption patterns: a cause for concern in light of increasing body weights. Am J Clin Nutr 2003; 78: 1068-73.

8. World Health Organization. Diet, nutrition and the prevention of chronic diseases. WHO Technical Report Series. Report No. 916. Geneva: WHO; 2003.

9. Gatenby S. Eating frequency: methodological and dietary aspects. Br J Nutr 1997; 77: S7-20.

10. de Castro JM. The time of day of food intake influences overall intake in humans. J Nutr 2004; 134: 104-11.
11. van Cauter E, Polonsky K, Scheen A. Roles of circadian rhythmicity and sleep in human glucose regulation. Endocr Rev 1997; 18: 716-38.

12. Nordic Council of Ministers. Nordic Nutrition Recommendations 2004. Report No. Nord 2004:13. Copenhagen: Nordic Council of Ministers; 2004: 85-102.

13. Swedish National Food Administration. Mat för småbarn - från 1 till 6 år. Handbok. Uppsala: Livsmedelsverket; 2002.

14. Sepp H, Lennernäs M, Pettersson R, Abrahamsson L. Children's nutrient intake at preschool and at home. Acta Paediatr 2001; 90: 483-91.

15. Sepp H. Pre-school children's food habits and meal situation. Factors influencing the dietary intake at preschool in a Swedish municipality. Uppsala: Uppsala University; 2002.

16. Swedish National Food Administration. The Meal Model. Swedish National Food Administration; 1997.

17. Swedish National Food Administration. Matcirkeln (the food circle). www.slv.se; 2006.

18. Nordin M. MATs. A nutrient calculation system designed for research and education, 4.0 edn. Västerås: Rudans Lättdata; 1997.

19. Sepp H, Lennernäs M, Abrahamsson L, Risvik E. The contribution of food groups to the nutrient intake and food pattern among preschool children. Food Quality and Preference 2002; 13: 107-16.

20. Lyhne N, Ovesen L. Added sugars and nutrient density in the diet of Danish children. Scand J Nutr 1999; 43: 4-7.

21. Ludwig DS, Peterson KE, Gortmaker SL. Relation between consumption of sugar-sweetened drinks and childhood obesity: a prospective, observational analysis. Lancet 2001; 357: 505-8.

22. McConahy KL, Smiciklas-Wright H, Birch LL, Mitchell DC, Picciano MF. Food portions are positively related to energy intake and body weight in early childhood. $\mathbf{J}$ Pediatr 2002; 140: 340-7.

23. Nicklas TA, Yang SJ, Baranowski T, Zakeri I, Berenson G. Eating pattern and obesity in children. The Bogalusa Study. Am J Prev Med 2003; 25: 9-16.

24. Kearney JM, Hulshof KF, Gibney MJ. Eating patterns - temporal distribution, converging and diverging foods, meals eaten inside and outside of the home - implications for developing FBDG. Public Health Nutr 2001; 4: 693-8.

25. Drummond S, Crombie N, Kirk T. A critique of the effects of snacking on body weight status. Eur J Clin Nutr 1996; 50: 779-83.

26. Bruce Å. Svenska näringsrekommendationer. Vår Föda 1981; 33: 354-72.

\footnotetext{
Lillemor Abrahamsson

Department of Domestic Sciences

Dag Hammarskjölds väg 21

Department of Domestic Sciences

SE-752 37 Uppsala

Sweden

Tel: + 46 7047।1943

Fax: + 46 18 47|226|

E-mail: Lillemor.Abrahamsson@ihv.uu.se
} 